\title{
PENINGKATAN PENGETAHUAN ERGONOMI DAN KETERAMPILAN PEREGANGAN OTOT LEHER UNTUK MENCEGAH NYERI LEHER
}

\author{
Yanti Harjono Hadiwiardjo ${ }^{1}$, Mila Citrawati ${ }^{2}$ \\ ${ }^{1}$ Departemen IKK IKM Fakultas Kedokteran, Universitas Pembangunan National Veteran Jakarta \\ ${ }^{2}$ Departemen Fisiologi Fakultas Kedokteran, Universitas Pembangunan National Veteran Jakarta \\ ${ }^{1}$ yantiharjono@upnvj.ac.id
}

\begin{abstract}
Fourth grade medical faculty students of Pembangunan Nsional Univrsity (UPN) had longer duration of sitting in front of laptop and computers due to scientific writing. This condition caused musculoskeletal pain especially neck pain, so there should be effort to avoid this complain. The effort to avoid neck pain was by couselling of ergonomics knowledge and muscular strecthing skill. Counselling was followed by 31 fourth grade students. After counselling there was increasing median knowledge score (before counselling the median score was 60 and after counselling median score was 70). The Wilcoxon test result showed $p$ value $=0.001$, it meant that there was difference of knowledge score before and after counselling. Meanwhile, result of muscular stretching exercise showed decreasing index score of disability caused by neck pain from 4 to 1 . Wilcoxon test result showed $p$ value $=0.001$ which meant that there was difference between index score of disability caused by neck pain befor and after exercise.
\end{abstract}

Keywords: ergonomics knowledge, neck muscular stretching, neck pain.

\begin{abstract}
Abstrak
Mahasiswa tingkat 4 Fakultas Kedokteran Universitas Pembangunan Nasional (UPN) Veteran Jakarta lebih lama berada di depan laptop atau komputer karena terdapat tambahan beban skripsi dan hal tersebut menimbulkan nyeri terutama nyeri leher sehingga perlu dilakukan upaya mencegah hal tersebut dengan upaya pemberian edukasi berupa pemberian pengetahuan ergonomi dan keterampilan peregangan otot. Kegiatan pemberian edukasi ini diikuti oleh 31 mahasiswa tingkat 4 UPN. Pada hasil pemberian edukasi didapatkan peningkatan median nilai pengetahuan dari sebelum pemberian edukasi dari 60 menjadi 70 dan hasil uji Wilcoxon menunjukkan $p=0.001$ yang berarti terdapat perbedaan nilai pengetahuan antara sebelum dan sesudah pemberian edukasi. Hasil dari keterampilan peregangan otot dapat dilihat terdapat penurunan nilai median skor indeks ketidakmampuan akibat nyeri leher dari sebelum pelatihan peregangan otot leher yaitu dari 4 menjadi 1 dan hasil Wilxocon menunjukkan nilai $p=$ value $=0.001$ yang berarti terdapat perbedaan antara skor indeks ketidakmampuan akibat nyeri leher sebelum dan sesudah pelatihan peregangan otot leher
\end{abstract}

Kata kunci: pengetahuan ergonomi, peregangan otot leher, nyeri leher

\begin{tabular}{l|l|l} 
Submitted: $2021-02-01$ & Revised: $2021-07-25$ & Accepted: $2021-10-30$ \\
\hline
\end{tabular}

\section{Pendahuluan}

Lembaga pendidikan merupakan salah satu sektor yang saat ini terdampak pandemi Covid19 karena inti dari proses pendidikan yang ada pada lembaga pendidikan adalah pembelajaran. Dalam rangka pencegahan penyebaran corona Kementerian Pendidikan dan Kebudayaan (Kemendikbud) mengeluarkan Surat Edaran dari Menteri Pendidikan dan Kebudayaan Nomor: 36962/MPK.A/HK/2020 tertanggal 17 Maret 2020 tentang Pembelajaran secara Daring dan Bekerja dari Rumah. Alternatif yang digunakan oleh setiap universitas untuk melaksanakan proses belajar mengajar adalah Pembelajaran Jarak Jauh (PJJ) yang merupakan keputusan proses belajar yang diambil oleh universitas agar tujuan dari pendidikan tetap dapat dilaksankan secara efisien dan efektif (Argaheni, 2020) Dukungan perangkat-perangkat mobile seperti laptop dan komputer diperlukan dalam pelaksanaan pembelajaran daring.(Sadikin \& Hamidah, 2020) 
Dalam pelaksanaan pembelajaran daring terjadi perubahan dari aktivitas mahasiswa ditandai dengan peningkatan frekuensi penggunaan perangkat-perangkat mobile dan lebih banyak duduk dibandingkan bergerak dan lebih banyak aktifitas digital dibanding akivitas fisik. (Fathimahhayati, Pawitra, \& Tambunan, 2020). Penggunaan perangkat mobile seperti laptop memungkinkan berbagai postur dalam bekerja dari duduk di kursi dengan laptop di pangkuan hingga di tempat tidur yang dapat menimbulkan gangguan muskuloskeletal sehingga menimbulkan nyeri. (Vora \& Hospital, 2020)

Gangguan muskuloskeletal di leher, bahu, lengan dan tangan dapat terjadi akibat aktivitas otot yang statis yang berkepanjangan (Bodin, Berglund, \& Forsman, 2019) Hasil penelitian yang dilakukan oleh Bhardwaj menyatakan bahwa kejadian nyeri leher sangat tinggi pada mahasiswa yang menggunakan komputer dalam jangka waktu lama (Bhardwaj \& Mahajan, 2015).

Waktu yang dihabiskan dengan lama di depan layar sentuh, komputer tablet, atau komputer dengan keyboard dapat juga menyebabkan postur tubuh yang buruk dan gerakan yang berulang pada individu dengan mengurangi tingkat aktivitas fisik mereka. Beberapa studi dalam literatur tentang bagaimana menentukan dan memecahkan masalah tersebut di atas menyatakan bahwa latihan postur dapat membuat posisi tubuh yang benar dan mengurangi masalah sistem muskuloskeletal dengan meningkatkan kesadaran ergonomi pada individu (Aytar, Altintaş, \& Aytar, 2020)

Gangguan muskuloskeletal juga dapat disebabkan karena lamanya bekerja pada tempat yang kurang ergonomis. Faktor ergonomi yang merupakan faktor risiko dari pemakaian komputer yang berhubungan dengan gangguan muskuloskeletal adalah postur tubuh yang salah dan disain tempat kerja. Pekerjaan yang monoton dan lama akan meningkatkan risiko trauma kumulatif yang pada jangka panjang akan menimbulkan kecacatan. Nyeri sendi, kekakuan dan sirkulasi yang menurun dapat diakibatkan postur duduk yang tetap dan berkepanjangan. Dalam rangka upaya pencegahan ketidaknyamanan tersebut dan untuk memaksimalkan produktifitas diperlukan adanya pengetahuan mengenai ergonomi dan latihan (Sherif Sirajudeen \& Saad Mohamed Siddik, 2017). Salah satu tatalaksana yang paling sering digunakan dalam rangka untuk mengatasi nyeri leher adalah latihan. Latihan dapat mengurangi nyeri dan tegang pada leher akibat kerja serta meningkatkan mobilitas tubuh bagian atas serta kualitas hidup terkait kesehatan (Suni, Rinne, Tokola, Mänttäri, \& Vasankari, 2017).

Selama masa pandemi, mahasiswa Fakultas Kedokteran Universitas Pembangunan Nasional Veteran Jakarta juga melakukan kegiatan pembelajaran daring. Hal ini menyebabkan mahasiswa akan berada pada posisi statis atau dalam posisi duduk yang lama. Mahasiswa tingkat 4 akan lebih lama berada di depan laptop atau komputer karena terdapat tambahan beban skripsi dan hal tersebut menimbulkan nyeri terutama nyeri leher.

Permasalahan mahasiswa yang saat ini terjadi adalah keluhan yang berhubungan dengan lamanya aktifitas di depan layar yaitu nyeri muskuloskeletal. Nyeri tersebut dirasakan terutama pada leher, meskipun nyeri tersebut dirasakan pada bahu, punggung atas dan bahu. Hal ini terjadi disebabkan pada metode pembelajaran daring mahasiswa harus menjalani duduk di depan laptop atau komputer dalam jangka waktu yang cukup lama setiap harinya selama berbulan-bulan.

Solusi dalam penyelesaian permasalahan yang dihadapi mahasiswa adalah pemberian pengetahuan ergonomi dan keterampilan peregangan otot dalam mencegah nyeri otot leher melalui kegiatan Pengabdian kepada Masyarakat. Menurut Gupta (2015) memperbaiki postur faktor yang dapat meringankan gejala musculoskeletal adalah dengan memperbaiki posur tubuh(Gupta et al., 2015), sedangkan Phedy (2016) menyatakan bahwa faktor utama yang dapat meringankan gejala muskuloskeletal adalah latihan (Phedy \& Gatam, 2016)

Tujuan kegiatan pengabdian masyarakat (PKM) ini adalah dengan pemberian pengetahuan ergonomi diharapkan dapat memperbaiki postur sehingga dapat mencegah nyeri leher. Selain itu diajarkan keterampilan peregangan otot, diharapkan juga dapat mencegah nyeri leher. 
BERNAS:

Jurnal Pengabdian Kepada Masyarakat

\section{Metode}

Pengabdian kepada masyarakat dilaksanakan melalui kegiatan pemberian edukasi mengenai pengetahuan ergonomi yang baik dalam penggunaan komputer atau laptop dan pemberian keterampilan peregangan otot leher dalam upaya mencegah nyeri leher. Pemberian pengetahuan ergonomi dan latihan peregangan otot leher dilakukan secara daring dan media yang dipakai adalah Zoom dengan peserta 31 mahasiswa FK UPN Veteran Jakarta. Media yang digunakan dalam pemberian edukasi dan keterampilan peregangan otot leher adalah media presentasi. Pada pemberian ketrampilan peregangan otot leher dengan instrukturnya adalah pengabdi.

Alat yang digunakan untuk mengukur tingkat ketercapaian keberhasilan dari PKM ini berupa kuesioner yang diberikan dalam bentuk G-form. Kuesioner yang diberikan adalah kuesioner pengetahuan ergonomi untuk menilai keberhasilan pemberian edukasi pengetahuan ergonomi dan kuesioner indeks ketidakmampuan akibat nyeri leher untuk menilai keterampilan peregangan otot leher. Kuesioner pengetahuan ergonomi diberikan sebelum dan sesudah pemberian edukasi dan kuesioner indeks ketidakmapuan akibat nyeri leher diberikan sebelum dan sesudah 3 minggu latihan peregangan otot leher. Kuesioner juga dilengkapi biodata mahasiswa yaitu nama, jenis kelamin dan umur.

Terdapat langkah-langkah kegiatan PKM agar kegiatan dapat berjalan dengan baik dan mencapai tujuan, yaitu sebagai berikut:

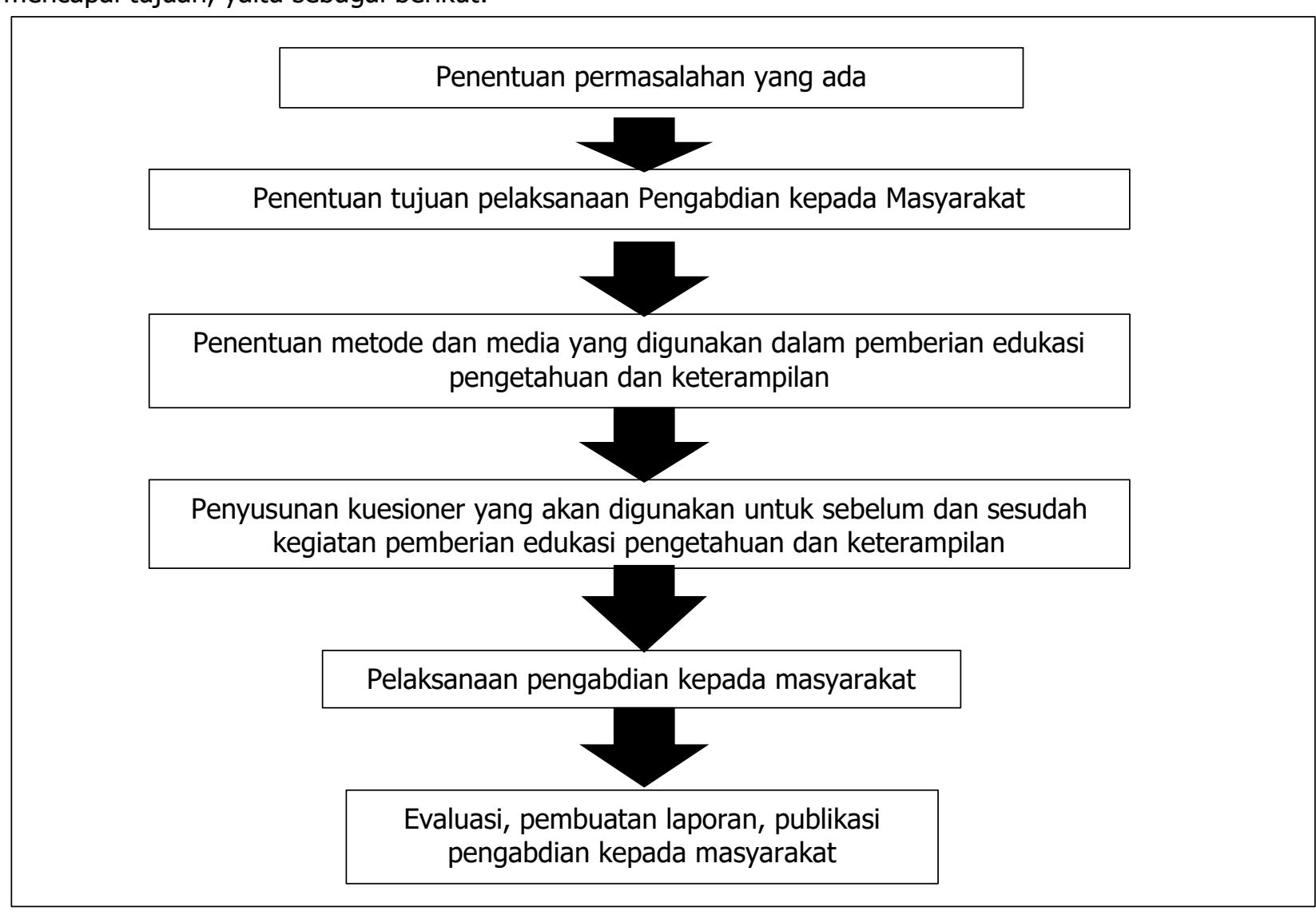

Gambar 1. Langkah-langkah Pelaksanaan Kegiatan Pengabdian kepada Masyarakat

Tingkat keberhasilan dari edukasi ergonomi dapat dilihat dari terjadinya peningkatan nilai pengetahuan ergonomi, sedangkan untuk menilai tingkat keberhasilan pemberian keterampilan peregangan dilihat dari berkurangnya skor indeks ketidakmampuan akibat nyeri leher. 


\section{Hasil dan Pembahasan}

Kegiatan PKM dilaksanakan pada bulan Oktober 2020. Pelaksanaan kegiatan dimulai dengan pembukaan yang kemudian dilanjutkan dengan pemberian tautan G-form untuk kuesioner pengetahuan ergonomi. Peserta diberikan waktu selama 15 menit untuk mengisi kuesioner dan setelah itu dilanjutkan dengan pemberian edukasi mengenai ergonomi. Topik ergonomi adalah mengenai posisi ergonomi yang baik sewaktu melakukan pembelajaran daring menggunakan laptop atau komputer dan upaya pencegahan nyeri otot leher. Kegiatan pemberian edukasi kemudian dilanjutkan dengan pemberian tautan $G$-form untuk pengisian kuesioner mengenai pengetahuan ergonomi. Kegiatan dilanjutkan dengan keterampilan peregangan otot leher, didahului dengan pemberian tautan $G$-form yang berisi kuesioner indeks ketidakmampuan akibat nyeri leher yang kemudian dilanjutkan dengan latihan peregangan otot leher dan peserta diminta untuk mengulangi latihan tersebut selama seminggu 3 kali dan dilakukan selama 3 minggu. Setelah 3 minggu kemudian peserta diminta untuk mengisi kembali kuesioner indeks ketidakmampuan akibat nyeri leher melalui $G$-form karena dengan peningkatan keterampilan peregangan otot dapat mengurangi indeks ketidakmampuan akibat nyeri leher.

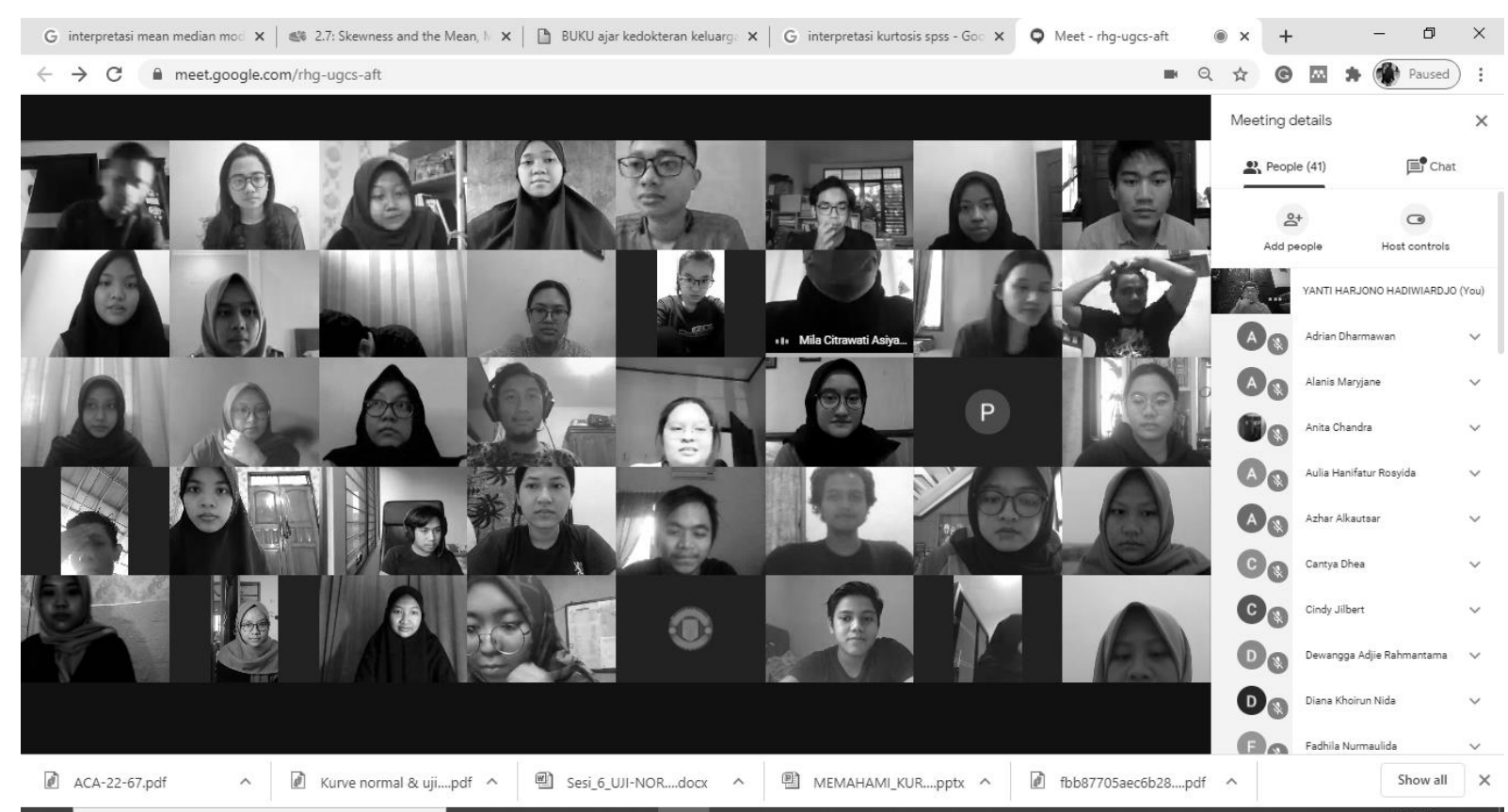

Gambar 2. Peserta pemberian edukasi ergonomi dan keterampilan peregangan otot 


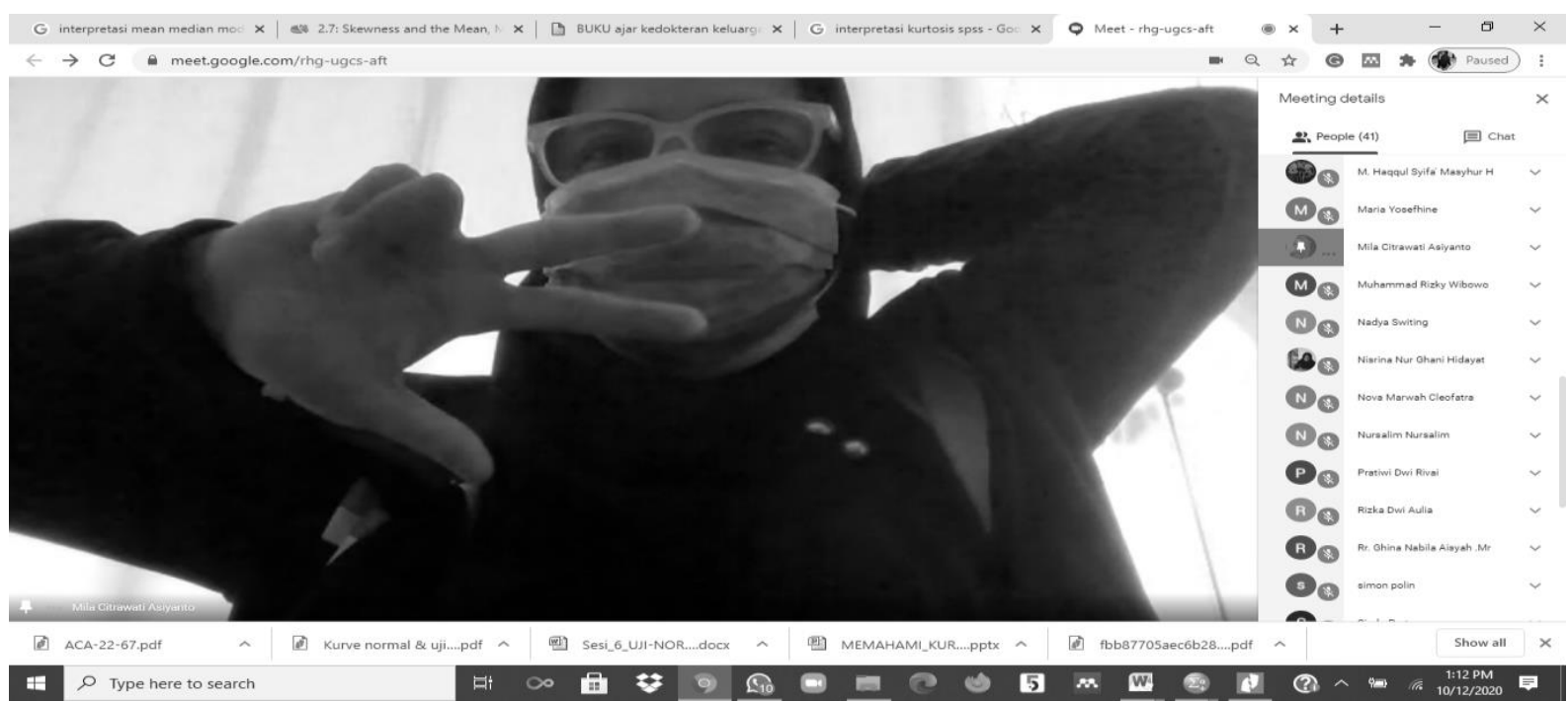

Gambar 3. Pemberian ketrampilan peregangan otot leher

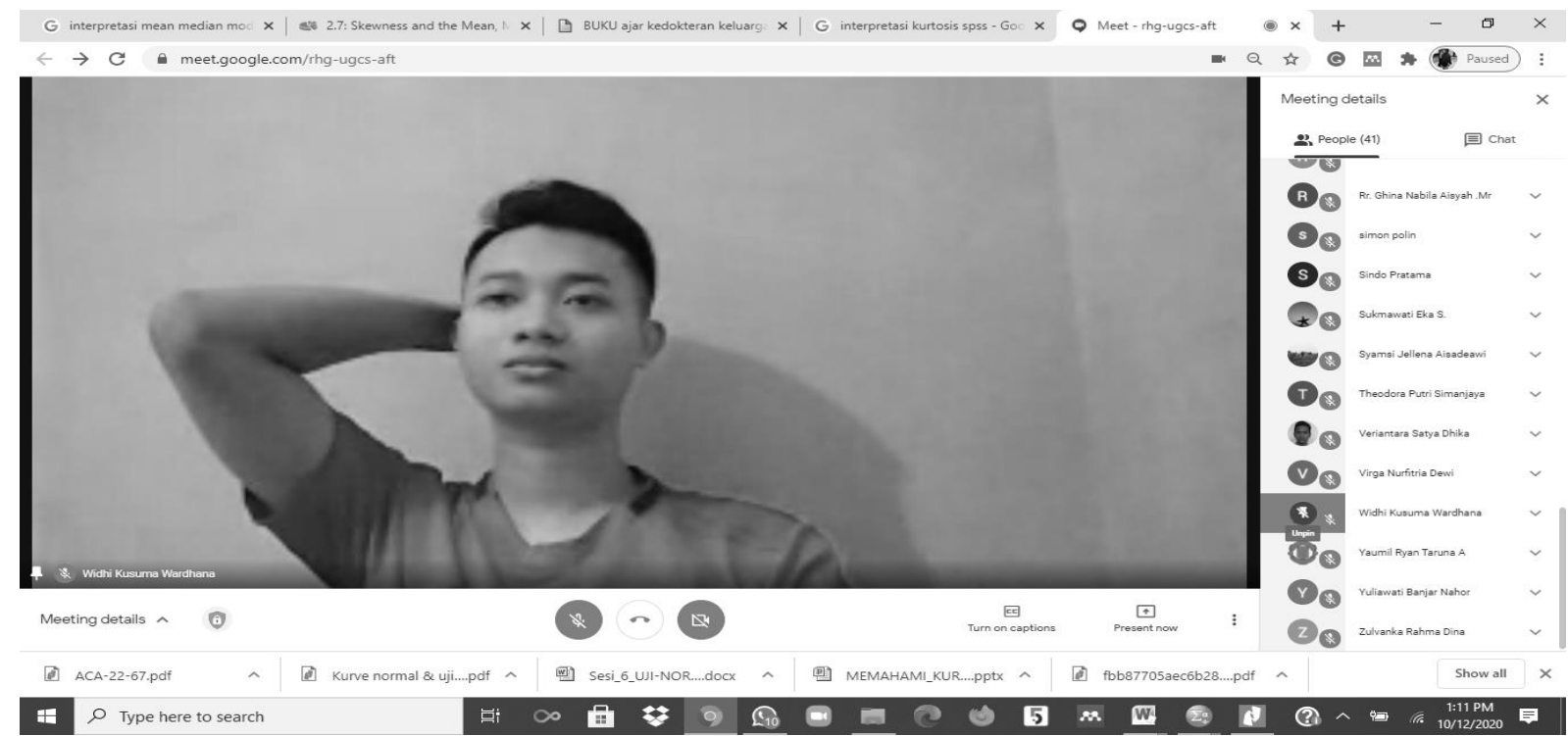

Gambar 3 Peserta peningkatan pengetahuan ergonomi dan keterampilan peregangan otot leher yang mengikuti gerakan instruktur

Kegiatan PKM mempunyai tujuan agar pengetahuan ergonomi dan keterampilan peregangan otot dari peserta meningkat sehingga diharapkan pengetahuan dan keterampilan tersebut dapat mencegah nyeri otot leher. Indikator untuk menilai keberhasilan dari kedua hal tersebut adalah nilai pengetahuan ergonomi meningkat dengan tolak ukur dinyatakan berhasil jika $80 \%$ dari peserta nilai pengetahuannya meningkat dan skor indeks ketidakmampuan akibat nyeri leher menurun dengan tolak ukur dinyatakan berhasil jika $80 \%$ dari peserta skor indeks ketidakmampuan akibat nyeri lehernya menurun.

Hasil dari kegiatan PKM dapat dilihat dari tabel dan gambar dibawah ini 
Tabel 1. Karakteristik jenis kelamin peserta peserta peningkatan pengetahuan ergonomi dan keterampilan peregangan otot leher

\begin{tabular}{lcc}
\hline Jenis Kelamin & Frekuensi & Persentase \\
\hline Laki-laki & 11 & 35.5 \\
Perempuan & 20 & 64.5 \\
\hline Total & 31 & 100 \\
\hline
\end{tabular}

Dari Tabel 1 dapat dilihat bahwa sebagian peserta peningkatan pengetahuan ergonomi dan keterampilan peregangan otot leher adalah perempuan yaitu sebanyak 20 orang atau $64.5 \%$

Tabel 2. Karakteristik umur peserta peningkatan pengetahuan ergonomi dan keterampilan peregangan otot leher

\begin{tabular}{lcc}
\hline & Frekuensi & Persentase \\
\hline 20 Tahun & 8 & 25.8 \\
21 Tahun & 21 & 67.7 \\
22 Tahun & 2 & 6.5 \\
\hline Total & 31 & 100 \\
\hline
\end{tabular}

Dari Tabel 2 dapat dilihat bahwa sebagian besar peserta peningkatan pengetahuan ergonomi dan keterampilan peregangan otot leher adalah berusia 21 yaitu sebanyak 21 orang atau $67.7 \%$

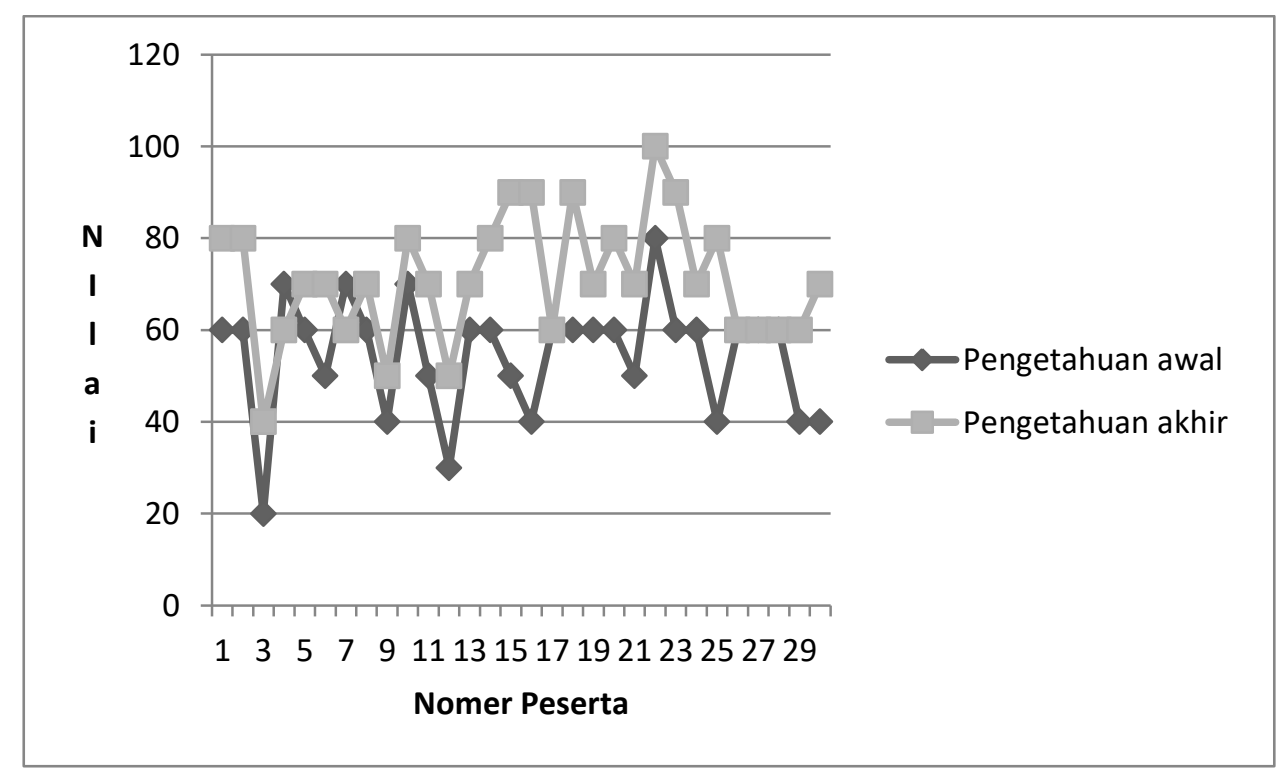

Gambar 3. Hasil nilai pengetahuan peserta peningkatan pengetahuan ergonomi dan keterampilan peregangan otot leher yang diberikan pada awal dan akhir kegiatan

Dari gambar di atas dapat dilihat bahwa sebagian besar peserta yaitu sebanyak 25 (80.64\%) peserta mengalami peningkatan nilai pengetahuan ergonomi. Hal ini menunjukkan bahwa lebih dari $80 \%$ peserta meningkat pengetahuan ergonominya, berarti kegiatan PKM dapat dikatakan berhasil. Hal ini juga sejalan dengan penelitian yang dilakukan oleh Devesh (2012) yang memperlihatkan nilai posttest relatif lebih tinggi dari pretest dan sebagian besar atau sebanyak $96.67 \%$ responden terjadi peningkatan nilai posttest jika dibandingkan dengan nilai pretest pada peningkatan pengetahuan tentang ergonomi untuk penggunaan komputer dengan menggunakan 
program pengajaran yang direncanakan diantara staf yang terpilih dari Perguruan tinggi MajanOman.

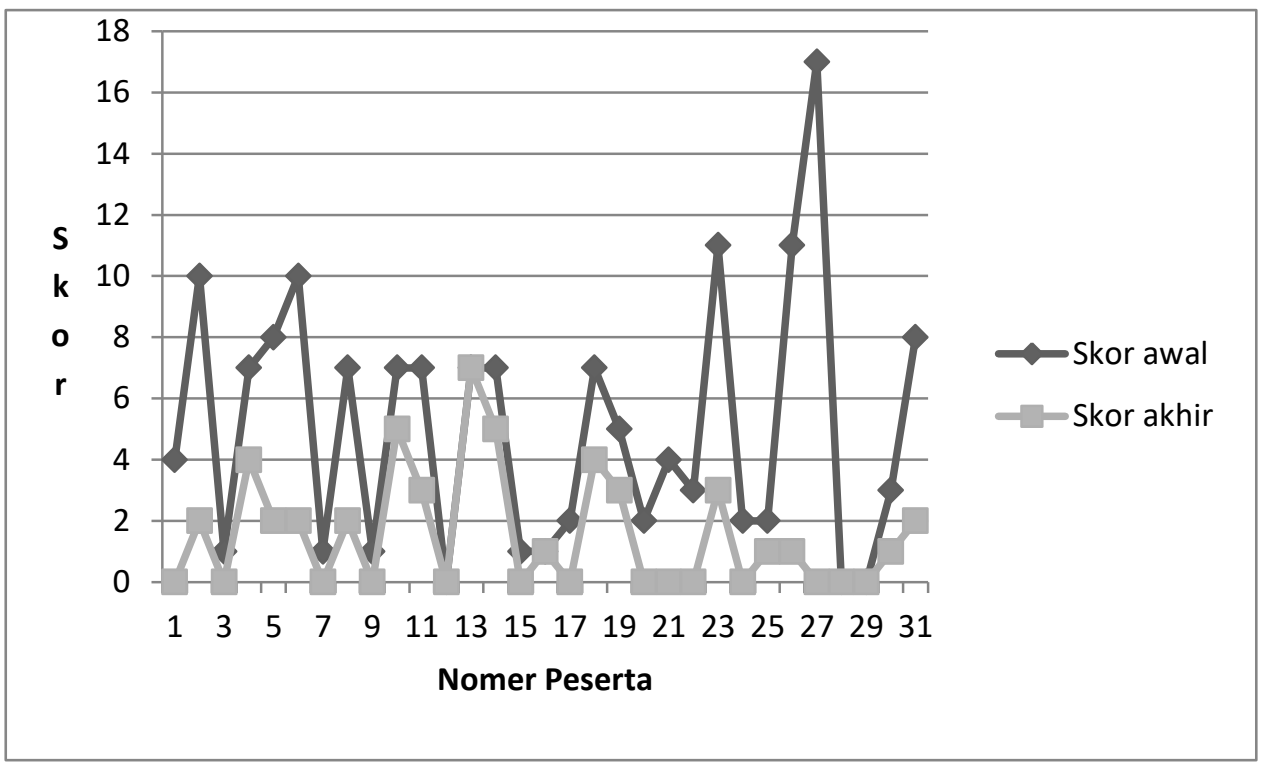

Gambar 3. Hasil skor indeks ketidakmampuan akibat nyeri leher peserta peningkatan pengetahuan ergonomi dan keterampilan peregangan otot yang diberikan pada awal dan akhir kegiatan (3 minggu setelah latihan peregangan otot leher)

Dari gambar di atas dapat dilihat bahwa sebagian besar dari peserta yaitu sebanyak 26 $(83.87 \%)$ peserta mengalami penurunan skor indeks ketidakmampuan akibat nyeri leher. Hal ini menunjukkan bahwa lebih dari $80 \%$ peserta mengalami penurunan skor indeks ketidakmampuan akibat nyeri leher sehingga dapat disimpulkan kegiatan PKM ini dapat dikatakan berhasil.

Tabel 3. Perbedaan tingkat pengetahuan ergonomi

\begin{tabular}{|c|c|c|c|}
\hline & $\mathrm{N}$ & $\begin{array}{l}\text { Median (minimum- } \\
\text { maksimum) }\end{array}$ & P-value \\
\hline $\begin{array}{l}\text { Pengetahuan sebelum pemberian } \\
\text { edukasi }\end{array}$ & 31 & $60(20-80)$ & \multirow{2}{*}{0.001} \\
\hline $\begin{array}{l}\text { Pengetahuan sesudah pemberian } \\
\text { edukasi }\end{array}$ & 31 & $70(40-100)$ & \\
\hline
\end{tabular}

Hasil dari tabel 4 memperlihatkan bahwa terdapat peningkatan pengetahuan dari sebelum dan sesudah pemberian edukasi pengetahuan ergonomi dengan melihat peningkatan median dari 60 pada sebelum pemberian edukasi dan 70 sesudah edukasi. Pada uji statistik didapatkan nilai $p$ $=0.001$ yang berarti terdapat perbedaan nilai pengetahuan sebelum dan sesudah pemebrian edukasi. Hal ini sejalan dengan dengan penelitian yang dilakukan oleh Abdallah et al (2019) yaitu didapatkan peningkatan nilai rata-rata pengetahuan pada sebelum, sesudah dan follow up pemberian edukasi yang artinya setelah pemberian edukasi mengenai ergonomi terjadi peningkatkan pengetahuan mengenai ergonomi pada anak sekolah dasar dan juga nilai $p$ sebesar 0.000 yang berarti secara statistik terdapat perbedaan bermakna antara sebelum, sesudah dan follow up pemberian edukasi (Abdallah, Abdou, \& Elrehim, 2019). Hasil ini sejalan juga dengan pengabdian kepada masyarakat yang dilakukan oleh Masrikhiyah (2020) dimana terdapat 
peningkatan pengetahuan ibu mengenai gizi seimbang dalam pemenuhan gizi keluarga yaitu dari $12 \%$ menjadi $76 \%$ setelah diberikan penyuluhan(Masrikhiyah, 2020)

Tabel. 4 Perbedaan skor indeks ketidakmampuan akibat nyeri leher

\begin{tabular}{lccc}
\hline & $\mathrm{N}$ & $\begin{array}{c}\text { Median (minimum- } \\
\text { maksimum) }\end{array}$ & Nilai p \\
\hline $\begin{array}{l}\text { Keluhan sebelum pelatihan peregangan } \\
\text { otot leher }\end{array}$ & 31 & $4(0-17)$ & 0.001 \\
$\begin{array}{l}\text { Keluhan sesudah pelatihan peregangan } \\
\text { otot leher }\end{array}$ & 31 & $1(0-7)$ & \\
\hline
\end{tabular}

Hasil dari tabel 5 memperlihatkan bahwa terdapat penurunan keluhan dari sebelum pelatihan peregangan otot leher dengan melihat penurunan median skor indeks ketidakmampuan akibat nyeri leher dari 4 menjadi 1 . Pada uji statistik didapatkan nilai $p=0.001$ yang berarti terdapat perbedaan antara skor indeks ketidakmampuan akibat nyeri leher sebelum dan sesudah pelatihan peregangan otot leher. Hal ini sesuai dengan kegiatan PKM yang dilakukan oleh Budhyanti et al. (2020) pada pegawai Sekolah Menengah Kejuruan Negeri 10 Cawang memperlihatkan bahwa setelah melakukan peregangan prevalensi kejadian nyeri leher menurun sebanyak $27.6 \%$ (Budhyanti, Anggiat, \& Juwita, 2020). Kegiatan Pengabdian kepada masyarakat ini juga sejalan dengan penelitian yang dilakukan oleh Aziz et al. (2016) yang memperlihatkan bahwa terjadi penurunan rata-rata indeks ketidakmampuan leher dan terdapat perbedaan antara sebelum dan sesudah latihan dengan Mc Kenzie dalam penurunan nyeri leher dan punggung (Aziz et al., 2016).Menurut Kachanathu et al. (2014) pada dekade terakhir sejumlah penelitian menunjukkan bahwa peregangan dan penguatan dari otot leher pada pasien dengan nyeri leher kronik dapat menurunkan nyeri leher (Kachanathu et al., 2014)

\section{Kesimpulan}

Kesimpulan yang didapat dari kegiatan PKM yang telah dilaksanakan dapat diuraikan sebagai berikut :

a. Kegiatan PKM ini berhasil meningkat pengetahuan mahasiswa sebagai peserta peningkatan pengetahuan ergonomi dan keterampilan peregangan otot leher mengenai ergonomi.

b. Kegiatan PKM ini berhasil menurunkan indeks ketidakmampuan akibat nyeri leher dari mahasiswa sebagai peserta peningkatan pengetahuan ergonomi dan keterampilan peregangan otot leher.

c. Hasil dari peningkatkan pengetahuan ergonomi diharapkan dapat merubah perilaku mahasiswa dalam hal penerapan ergonomi sehingga dapat mencegah nyeri leher.

\section{Daftar Pustaka}

Abdallah, L. S., Abdou, N. M., \& Elrehim, A. I. A. (2019). Effect of computer related ergonomics intervention on knowledge and practice of primary school children. Indian Journal of Public Health Research and Development, 10(10), 1776-1781. https://doi.org/10.5958/09765506.2019.03101.2

Argaheni, N. B. (2020). Sistematik Review: Dampak Perkuliahan Daring Saat Pandemi COVID-19 Terhadap Mahasiswa Indonesia. PLACENTUM: Jurnal IImiah Kesehatan Dan Aplikasinya, 8(2), 99. https://doi.org/10.20961/placentum.v8i2.43008

Aytar, A., Altintaş, A., \& Aytar, A. (2020). Effects of posture and ergonomics training for students receiving distance education during the covid-19 pandemic on musculoskeletal pain, exercise 
behavior decision-making balance, and physical activity level. Journal of Exercise Therapy And Rehabilitation, 7(2), 137-144. Retrieved from www.jetr.org.trJOURNALOF

Aziz, S., Ilyas, S., Imran, S., Yamin, F., Zakir, A., Atiq-ur-Rehman, ... Khanzada, S. (2016). Effectiveness of Mc Kenzie Exercises in Reducing Neck and Back Pain among Madrassa Students. International Journal of Physiotherapy, 3(1). https://doi.org/10.15621/ijphy/2016/v3i1/88916

Bhardwaj, Y., \& Mahajan, R. (2015). Prevalence of Neck Pain and Disability in Computer Users. International Journal of Science and Research (IJSR), 6(8), 1288-1290. Retrieved from https://www.ijsr.net/archive/v6i8/ART20176253.pdf

Bodin, T., Berglund, K., \& Forsman, M. (2019). Activity in neck-shoulder and lower arm muscles during computer and smartphone work. International Journal of Industrial Ergonomics, 74(October), 102870. https://doi.org/10.1016/j.ergon.2019.102870

Budhyanti, W., Anggiat, L., \& Juwita, C. P. (2020). Pencegahan Dan Penanganan Nyeri Leher Dan Punggung Bawah Dengan Peregangan Mandiri Pada Pegawai Sekolah Menengah Kejuruan Negeri 10 Cawang. Jurnal Fisioterapi Dan Rehabilitasi, 4(1), 79-89. https://doi.org/10.33660/jfrwhs.v4i1.105

Fathimahhayati, L. D., Pawitra, T. A., \& Tambunan, W. (2020). Analisis ergonomi pada perkuliahan daring menggunakan smartphone selama masa pandemi covid-19: studi kasus mahasiswa Prodi Teknik Industri Universitas Mulawarman. Operations Excellence: Journal of Applied Industrial Engineering, 12(3), 309. https://doi.org/10.22441/oe.2020.v12.i3.004

Gupta, D., Mathur, A., Patil, G. I., Tippanawar, H. K., Jain, A., \& Jaggi, N. (2015). Prevalence of musculoskeletal disorder and alternative medicine therapies among dentists of North India: A descriptive study. Pharmacognosy Research, 74), 350-354. https://doi.org/10.4103/09748490.157810

Kachanathu, S. J., Philip, S., Nuhmani, S., Natho, Mo., Melam, G., \& Buragadda, S. (2014). A Comparative Study on Effect of Different Positional Isometric Neck Exercises Training On Neck Pain and Functional Ability in Patients with Neck Pain, 2, 91-95.

Masrikhiyah, R. (2020). Peningkatan Pengetahuan Ibu Mengenai Gizi Seimbang Dalam Pemenuhan Gizi Keluarga. Dinamisia: Jurnal Pengabdian Kepada Masyarakat, 4(3), 476-481. https://doi.org/10.31849/dinamisia.v4i3.3636

Phedy, P., \& Gatam, L. (2016). Prevalence and associated factors of musculoskeletal disorders among young dentists in Indonesia. Malaysian Orthopaedic Journal, 102), 1-5. https://doi.org/10.5704/MOJ.1607.001

Sadikin, A., \& Hamidah, A. (2020). Pembelajaran Daring di Tengah Wabah Covid-19. Biodik, 6(2), 109-119. https://doi.org/10.22437/bio.v6i2.9759

Sherif Sirajudeen, M., \& Saad Mohamed Siddik, S. (2017). Knowledge of Computer Ergonomics among Computer Science Engineering and Information Technology Students in Karnataka, India. Asian Journal of Pharmaceutical Research and Health Care, 9(2), 64. https://doi.org/10.18311/ajprhc/2017/11023

Suni, J. H., Rinne, M., Tokola, K., Mänttäri, A., \& Vasankari, T. (2017). Effectiveness of a standardised exercise programme for recurrent neck and low back pain: A multicentre, randomised, two-arm, parallel group trial across 34 fitness clubs in Finland. BMJ Open Sport and Exercise Medicine, 3(1). https://doi.org/10.1136/bmjsem-2017-000233

Vora, T. D., \& Hospital, B. Y. L. N. C. (2020). " A Survey of Musculoskeletal Symptoms Asssociated with Work From Home Culture in COVID 19, (September), 4-6. 